\title{
Dominant Causes for Failure in Mathematics by Engineering Students using Induced and Extended Fuzzy Clustering Model
}

\author{
A. Praveen Prakash \\ Department of Mathematics \\ Hindustan University \\ Padur, Chennai - 603103
}

\author{
J. Esther Jerlin \\ Department of Mathematics \\ Hindustan University \\ Padur, Chennai - 603103
}

\author{
M.P. Kannan \\ Department of Mathematics \\ Hindustan University \\ Padur, Chennai - 603103
}

\begin{abstract}
An article published on Feb 5 $5^{\text {th }}, 2013$ in 'THE HINDU' states that "Anna University results fail to add up i.e Majority of the engineering students keep arrears in engineering mathematics than other papers. This year, nearly 60 percent of second-year Anna University students have failed in the mathematics paper in their third semester. 'In a class of 75 in electronics and communications engineering (ECE), nearly 50 have arrears in mathematics and this is supposed to be the brightest class, as many of the students were in the toppers in the class XII board exams,' says a third-year ECE student of the college of Engineering, Guindy. Teachers say that it is an ever-growing problem". As a remedial measure Anna University has introduced Bridge course at the entry level to ensure that the students are equipped with the basics of maths to make a smooth entry into the pursuit of engineering mathematics. We have taken this universal problem for our study in order to identify the dominant causes for such failure to take place. We have analysed this study using the newly proposed model called Induced and Extended Fuzzy Clustering Model (IEFCLM). We have discussed the study in five sections. Section one gives the description of the problem. Section two gives the description of Induced Extended Fuzzy Clustering model. In section three the problem is analysed using IEFCLM. The fourth section deals with the results and discussions and section five deals with the conclusion and suggestions based on the study.
\end{abstract}

\section{Keywords}

FCMs, IFCMs, IEFCLM, Hidden pattern, fixed point, Engineering Mathematics, Failure.

\section{INTRODUCTION}

Engineering is considered as one of the professional courses universally. There are around 552 Engineering colleges existing in Tamil Nadu. Most students prefer to join in engineering courses by their own interest but some out of compulsion by others. But this course makes the individual to be proud of saying that he or she is an engineer. Compared to other subjects students feel hard to learn and apply Engineering mathematics. But the fact is mathematical concepts are widely used in most of the engineering subjects in order to solve all kinds of critical and innovative problems assigned to them. In this paper, we analyze the causes for failures in mathematics among the engineering students of Tamil Nadu by interviewing and collecting the data from the students, teachers, parents and management. We found that each section of the respondents blaming the other. FCM concludes the problem by obtaining the attributes affecting it in on-off state. IFCM, a betterment of FCM, obtains the result through the occurrence of maximum number of attributes resulting in on state. Fuzzy clustering is the tool which permits the attributes to share its position in different clusters according to its membership value. Extended Fuzzy clustering is the improvement of Fuzzy Clustering method to obtain the dominant cluster of attributes that relate to the study of the problem using on-off state. Now the proposed new model called Induced Extended Fuzzy Clustering is the combination of IFCM and Extended Fuzzy Clustering method. The objective of the model is to obtain the major causes for the problem through IFCM and then apply Extended Fuzzy Clustering Model to obtain the dominant causes among them.

\section{FUZZY COGNITIVE MAP (IFCM) 2.1 Algorithm to use Induced Fuzzy Cognitive Maps (IFCM)}

IFCM with the basis of FCM has been developed with an advantage of getting the optimal solution in refined manner.

Step-1: From the concerned expert obtain the attributes for the problem. It acts as an unsupervised data. The directed graph is drawn with the help of expert's opinion.

Step-2: Connection matrix is framed from the directed graph.

Step-3: Let we take the state victor $\mathrm{C}_{1}$ which is in on position. Find $\mathrm{C}_{1} * \mathrm{M}$. The resultant vector is updated and threshold at each stage.

Step-4: Threshold value is computed by giving 1 for the values $>1$ and 0 for the values $<0$.

Step-5: Now each component in the $C_{1}$ vector is taken separately and passed to the connection matrix. The vector having maximum number of one's is found and considered as $\mathrm{C}_{2}$.

Step-6: When the same threshold value occurs twice. The value is considered as the fixed point. The iteration gets terminated.

\subsection{Algorithm to find a Membership values for the Attributes \\ STEP 1: Start}

STEP 2: Fix, the values of 6 attributes on a 10-point rating scale in a set $\mathrm{D}$ (say)

STEP 3: Fix the cluster, which is defined as Cluster $1=$ LOW, whose range beginning with 2 (bv1) End with 5 (ev1). Cluster $2=$ MODERATE, whose range beginning with 3 (bv2) end with 8 (ev2). Cluster $3=\mathrm{HIGH}$, whose range beginning with 7 (bv3) end with 10 (ev3).

STEP 4: Choose en element $x$ in $D$

STEP 5: If $x<$ ev1, Go to STEP 6, else Go to STEP 8 
STEP 6: If $x>b v 2$, then $x$ lies in cluster 1 and cluster 2 whose membership value is defined as $\mu \mathrm{k}(\mathrm{x})=\mathrm{ev1-x}$ : $\mathrm{x}$ - bv2, Go to STEP 12, else Go to STEP 7.

STEP 7: Then $x$ lies in cluster 1 only, the membership value is $\mu \mathrm{k}(\mathrm{x})=1$ Go to STEP 12

STEP 8: If $x$ < ev2 Go to STEP 9, else Go to STEP 11

STEP 9: If $x>$ bv3, then $x$ lies in cluster 2 and cluster 3, whose membership value is defined as $\mu \mathrm{k}(\mathrm{x})=\mathrm{ev} 2-\mathrm{x}$ : $\mathrm{x}-\mathrm{bv} 3$, Go to step 12, else Go to STEP10

STEP 10: Then $x$ lies in cluster 2 only, the membership value is $\mu \mathrm{k}(\mathrm{x})=1$ else Go to STEP11

STEP 11: Then $x$ lies in cluster 3 only, the membership value is $\mu \mathrm{k}(\mathrm{x})=1$

STEP 12: Go to STEP 4, until all the values in D have been checked

STEP 13: Stop

Here 'bv' denotes the beginning value and 'ev' denotes the ending value.

\subsection{Algorithm to find a Membership values for the Attributes for the Extended Fuzzy Clustering Model \\ STEP 1: Start}

STEP 2: Select a value $\mathrm{x}$ from the corresponding row of Table 1. GOTO STEP 3.

STEP 3: Get the values of $\mathrm{L}, \mathrm{M}$, and $\mathrm{H}$ for the corresponding $\mathrm{x}$ of Table 1 . GOTO STEP 4 .

STEP 4: If $(\mathrm{L}<=\mathrm{M})$ and if $(\mathrm{M}<=\mathrm{H})$, put $\mathrm{H}=1$ else $\mathrm{M}=1$, else GOTO STEP 7.

STEP5: If $(\mathrm{L}<=\mathrm{H})$ put $\mathrm{H}=1$ else $\mathrm{L}=1$. GOTO STEP 8.

STEP 6: GOTO STEP 2 until attaining all the membership value for the corresponding rows. GOTO STEP 9.

\section{STEP 7: Stop}

Here ' $\mathrm{X}$ ' denotes the Mean Value, 'L' denotes the LOW, 'M' denotes the Moderate and ' $\mathrm{H}$ ' denotes the High.

\section{AN ANALYSIS ON THE STUDY OF THE PROBLEM}

A collective opinion from the engineering students and faculty members have been considered as the following twelve attributes $\left(\mathrm{C}_{1}, \mathrm{C}_{2}, \ldots, \mathrm{C}_{12}\right)$ as the main nodes for our study The following twelve attributes are listed below.

$\mathrm{C}_{1}$-Higher Secondary Schools fail to provide understanding the basics of XI and XII std syllabus.

$\mathrm{C}_{2}$ - Lack of logical reasoning and application skill

$\mathrm{C}_{3}$-Teachers lack knowledge on teaching methodology

$\mathrm{C}_{4}$-Teachers lack knowledge on student psychology and hence fail to be kind and understanding

$\mathrm{C}_{5}$-Parents fail to identify the interest and admit them in courses of their own interest without finding the interest of students

$\mathrm{C}_{6}$-Students don't show interest and involvement in mathematics

$\mathrm{C}_{7}$ - Students are not regular to classes
$\mathrm{C}_{8}$ - Less involvement of teachers in class due to psychological factors

$\mathrm{C}_{9^{-}}$Lack of confidence among the students in solving the problem

$\mathrm{C}_{10^{-}}$Childhood aversion for Mathematics

$\mathrm{C}_{11}$-The Institution fails to provide good atmosphere to teacher - student relationship

$\mathrm{C}_{12}$-Teacher fails to continuously assess the student performance by tests/assignments

Based on the expert's opinion the following directed graph is drawn to show the inter-relationship among the attributes (i.e) the causal relation between the nodes.

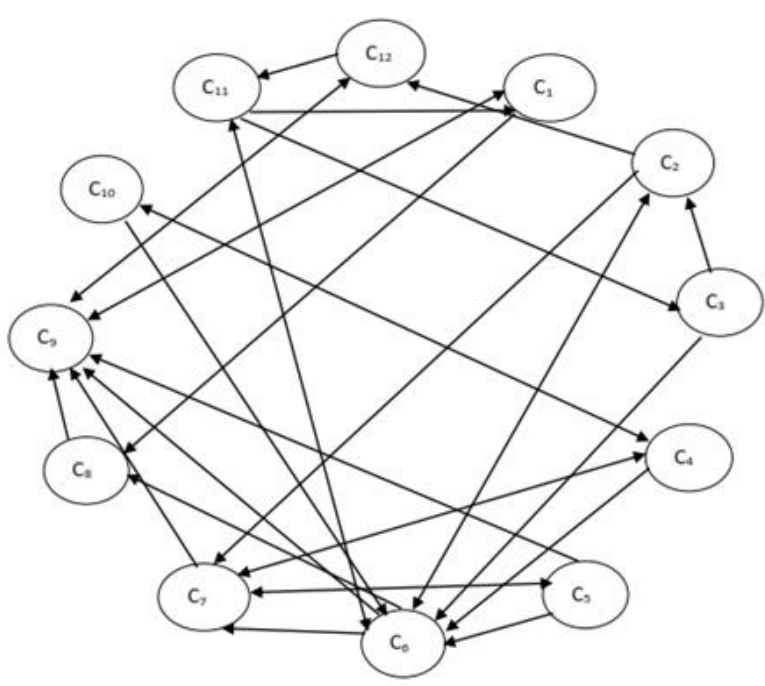

Fig: 1 Directed graph by expert's opinion

The corresponding connection matrix for the directed graph is given below.

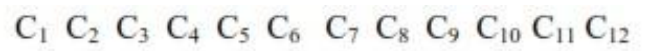

\begin{tabular}{|c|c|c|c|c|c|c|c|c|c|c|c|}
\hline $\mathrm{C}_{1}$ & & 0 & 0 & 0 & 0 & 0 & 0 & 1 & 1 & 0 & 0 \\
\hline $\mathrm{C}_{2}$ & 0 & 0 & 0 & 0 & 0 & 1 & 1 & & 0 & & 0 \\
\hline $\mathrm{C}_{3}$ & 0 & 1 & 0 & 0 & 0 & 1 & 0 & 0 & 0 & 0 & 0 \\
\hline $\mathrm{C}_{4}$ & 0 & 0 & 0 & 0 & 0 & 1 & 1 & 0 & 0 & 1 & 0 \\
\hline $\mathrm{C}_{5}$ & 0 & 0 & 0 & 0 & 0 & 1 & 1 & 0 & 1 & 0 & 0 \\
\hline $\mathrm{C}_{6}$ & 0 & 1 & 0 & 0 & 0 & 0 & 1 & 1 & 1 & U & 1 \\
\hline $\mathrm{C}_{7}$ & 0 & 0 & 0 & 1 & 1 & 0 & 0 & 0 & 1 & 0 & 0 \\
\hline $\mathrm{C}_{8}$ & 0 & 0 & 0 & 0 & 0 & 0 & 0 & 0 & 1 & 0 & 0 \\
\hline $\mathrm{C}_{9}$ & 1 & 0 & 0 & 0 & 0 & 0 & 0 & 0 & 0 & 0 & 0 \\
\hline $\mathrm{C}_{10}$ & 0 & 0 & 0 & 1 & 0 & 1 & 0 & 0 & 0 & 0 & 0 \\
\hline $\mathrm{C}_{11}$ & 1 & 0 & 1 & 0 & 0 & 1 & 0 & 0 & 0 & 0 & 0 \\
\hline $\mathrm{C}_{12}$ & & 0 & 0 & 0 & 0 & 0 & 0 & 0 & 1 & 0 & 1 \\
\hline
\end{tabular}

Fig: 2 Connection matrix for the directed graph

Now using the matrix E of the Fuzzy Cognitive Map (FCM), we determine the hidden pattern.

Process: 1

Suppose the concept $\mathrm{C}_{6}$ (i.e) Students don't show interest and involvement in mathematics is in the on state and another nodes are in the off sate. 
Let $\mathrm{C}_{1}=(000001000000)$

$$
\begin{aligned}
& \mathrm{C}_{1} \mathrm{E} \longrightarrow(010001111010)=C_{1}^{1} \\
& C_{1}^{1} \mathrm{E}=(010001111010) \times \mathrm{E} \\
& \begin{aligned}
C_{1}^{1} \mathrm{E} \sim & (000001000000) \times \mathrm{E} \longrightarrow(010000111010) \\
& =(010000000000) \times \mathrm{E} \longrightarrow(000001100001) \\
& =(000000100000) \times \mathrm{E} \longrightarrow(000110001000) \\
& =(000000010000) \times \mathrm{E} \longrightarrow(100000000001) \\
& =(000000001000) \times \mathrm{E} \longrightarrow(101001000000) \\
& =(000000000010) \times \mathrm{E} \longrightarrow
\end{aligned}
\end{aligned}
$$

Maximum number of 1's is $\mathrm{C}_{2}$ (i.e) either (101001000000) or (000110001000)

$$
\begin{aligned}
& \text { Consider } \mathrm{C}_{2}=(000110001000) \\
& \begin{aligned}
& \mathrm{C}_{2} \mathrm{E} \longrightarrow(100001101101)=C_{2}^{1} \\
& C_{2}^{1} \mathrm{E}=(100001101101) \times \mathrm{E} \\
& C_{2}^{1} \mathrm{E} \sim(000001000000) \times \mathrm{E} \longrightarrow(010000111010) \\
&=(100000000000) \times \mathrm{E} \longrightarrow(000000011000) \\
&=(000001000000) \times \mathrm{E} \longrightarrow(010000111010) \\
&=(000000100000) \times \mathrm{E} \longrightarrow(100000000001) \\
&=(000000001000) \times \mathrm{E} \longrightarrow(000101000000) \\
&=(000000000100) \times \mathrm{E} \longrightarrow(000000001010) \\
&=(000000000001) \times \mathrm{E} \longrightarrow
\end{aligned}
\end{aligned}
$$

Maximum number of 1's is $C_{3}$ (i.e) (010000111010)

Consider $\mathrm{C}_{3}=(010000111010)$

$$
\begin{aligned}
& \mathrm{C}_{3} \mathrm{E} \longrightarrow(101111101001)=C_{3}^{1} \\
& \begin{aligned}
& C_{3}^{1} \mathrm{E}=(101111101001) \times \mathrm{E} \\
& C_{3}^{1} \mathrm{E} \sim(000001000000) \times \mathrm{E} \longrightarrow(010000111010) \\
&=(100000000000) \times \mathrm{E} \longrightarrow(000000011000) \\
&=(001000000000) \times \mathrm{E} \longrightarrow(010001000000) \\
&=(000100000000) \times \mathrm{E} \longrightarrow(000001100100) \\
&=(000010000000) \times \mathrm{E} \longrightarrow(010000111010) \\
&=(000001000000) \times \mathrm{E} \longrightarrow(000110001000) \\
&=(000000100000) \times \mathrm{E} \longrightarrow(100000000001) \\
&=(000000001000) \times \mathrm{E} \longrightarrow(000000001010) \\
&=(000000000001) \times \mathrm{E} \longrightarrow
\end{aligned}
\end{aligned}
$$

Maximum number of 1's is $\mathrm{C}_{4}$ (i.e) (010000111010)

(i.e) $\mathrm{C}_{4}=(010000111010)$

Thus $\mathrm{C}_{3}=\mathrm{C}_{4}$

Therefore the fixed point is $(010000111010)$. Carrying the similar process to all other nodes in on state, we obtain the same fixed point as the dominant result.

\section{RESULTS AND DISCUSSIONS}

Based on the fixed point i. e (010000111010) obtained by IFCM, the respondents were invited to express their viewpoints. The following figure and tables show the result of our analysis. The analysis is carried on a 10-point rating scale.

The ratings and the Standard Deviation of the attributes have been subjected to fuzzy c-means clustering using algorithm (2.2) and the following results are shown in Table1 according to the expert's opinion. The following table 1 gives the 3 cluster combination.

The first cluster comprises of the attributes with average rating from 2 to 5 with a mid-value 3.5. The second cluster range is from 3 to 8 with a mid-value 5.5 and the third cluster has a range of 7-10 with a mid-value 8.5.

The first, second and third clusters range indicates the causes of failures in mathematics by engineering students show the low, moderate and high level of weightage. There is overlapping ranges as in characteristic of a fuzzy based cluster. For the 3-cluster Range of level of Dominant Cause (i.e)

Table 1. 3-cluster Range of level of Dominant Cause

\begin{tabular}{|c|c|c|c|}
\hline & Cluster 1 & Cluster 2 & Cluster 3 \\
\hline Range & $2.0-5.0$ & $3.0-8.0$ & $7.0-10$ \\
\hline Mid Value & 3.5 & 5.5 & 8.5 \\
\hline Classification & LOW & MEDIUM & HIGH \\
\hline
\end{tabular}

Mean Rating of dominant cause obtained from students of Engineering Colleges

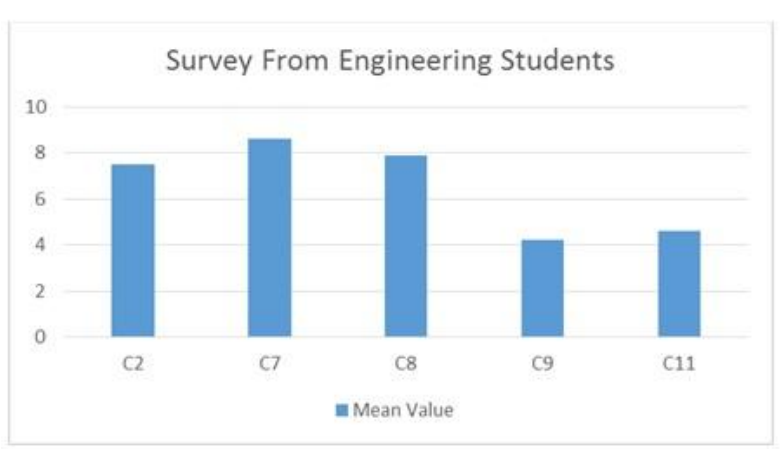

Fig: 3 Mean Rating of Dominant Cause obtained from Engineering Students

Table 2. Degree of Membership of Attributes

\begin{tabular}{|l|l|l|l|l|l|l|l|l|}
\hline Attributes & Mean & Low & Moderate & High & $\longrightarrow$ & Low & Moderate & High \\
\hline $\mathrm{C}_{2}$ & 7.5 & 0 & 0.5 & 0.5 & $\longrightarrow$ & 0 & 0 & 1 \\
\hline $\mathrm{C}_{7}$ & 8.6 & 0 & 0 & 1 & $\longrightarrow$ & 0 & 0 & 1 \\
\hline $\mathrm{C}_{8}$ & 7.9 & 0 & 0.1 & 0.9 & $\longrightarrow$ & 0 & 0 & 1 \\
\hline $\mathrm{C}_{9}$ & 4.2 & 0.4 & 0.6 & 0 & $\longrightarrow$ & 0 & 1 & 0 \\
\hline $\mathrm{C}_{11}$ & 4.6 & 0.2 & 0.8 & 0 & $\longrightarrow$ & 0 & 1 & 0 \\
\hline
\end{tabular}

Considering the responses obtained from the experts, degree of membership of the attributes that refer to the causes of failure in mathematics by engineering students is found using the above algorithm is shown in Table: 2 .

Attribute 7 with a mean rating 8.6 is entirely (100\%) with a membership value of 1 in cluster 3. (i.e.) High.

Attributes 9 and 11 with a mean ratings 4.2 and 4.6 belongs to $40 \%$ in cluster 1 and $60 \%$ in cluster 2 , and $20 \%$ in cluster 1 and $80 \%$ in cluster 2 (i.e.) between LOW and MODERATE. 
Attribute 2 and 8 with a mean ratings 7.5 and 7.9 belongs to $50 \%$ in cluster 2 and $50 \%$ in cluster 3 and $10 \%$ in cluster 2 and $90 \%$ in cluster 3 (i.e.) between MODERATE and HIGH.

\section{CONCLUSION AND SUGGESTIONS}

Degree of membership of the attributes obtained using the above algorithm shown in Table:2 and then thresholded and updated to obtain the on state and off state of the attributes among the three level of classifications, Low, Moderate and High.

On analysis it is found that no attributes come to the 'on state' in cluster 1. (i.e.) LOW level.

Attributes 9 and 11 with a mean ratings 4.2 and 4.6 come to the 'on state' in cluster 2. (i.e.) MODERATE level.

Attributes 2, 7 and 8 with a mean rating 7.5, 8.6 and 7.9 come to the 'on state' in cluster 3. (i.e.) HIGH level.

The Induced Extended Fuzzy Clustering analysis highlighted that among the five attributes taken for analysis we arrived that the attributes 7 and 8 (i.e)

$\mathrm{C}_{2}$ - Lack of logical reasoning and application skill

$\mathrm{C}_{7^{-}}$Students are not regular to classes

$\mathrm{C}_{8}$ - Less involvement of teachers in class due to psychological factors

are the dominant causes for the failure in mathematics by the engineering students among the listed. These attributes resulted in the on state after thresholding and updating in the high level of classification.

\section{REFERENCES}

[1] Kaufmann, "Introduction to the Theory of Fuzzy Subsets”, Academic Press, INC. (LONDON) LTD, 1975.

[2] Kosko, "Neural Networks and Fuzzy systems: A Dynamical System Approach to Machine Intelligence", Prentice Hall of India, 1997.

[3] W.B Vasantha Kandasamy and Smarandache Florentin; 'Fuzzy Cognitive Maps and Neutrosophic Cognitive Maps', Xiquan, Phoenix. (2003).

[4] H.J. Zimmermann, "Fuzzy Set Theory and its application", Fourth Edition Springer 2011.
[5] Fuzzy Clustering of the Domestic Violence for the Degree of Suicide thought based on Married Women Perception by A.Victor Devadoss, A.Felix,2012, IJERA p: $1770-1773$

[6] S. Narayanamoorthy and S.Kalaiselvan, "Adaptation of induced fuzzy cognitive maps to the problem faced by the power loom workers", I.J. Intelligent Systems and Applications, 2012, 9, 75-80.

[7] A.Praveen Prakash , J.Esther Jerlin and J.Bennilo Fernandes, "A Study on the causes for aversion to mathematics by engineering students using Fuzzy Cognitive Maps" (FCMs), International Journal of Innovative Research in Science, Engineering and Technology, ISSN: 2319-8753, Vol. 3, Issue 3, March 2014.

[8] A.Praveen Prakash , J.Esther Jerlin and J.Bennilo Fernandes, "A Study on the causes for failures in Mathematics by engineering students using Combined Fuzzy Clustering Model" (CFCLM)", International Journal of Computer Applications, ISBN: 973-93-8088176-7, Vol. 94- No 6, May 2014.

[9] A.Praveen Prakash ,M.P.Kannan and J.Esther Jerlin , "An Analysis on causes for failure in Mathematics by engineering students in Tamil Nadu using Combined Overlap Fuzzy Clustering Model"(COFCLM)", )", International Journal of Computer Applications, ISBN: 973-93-80881-76-7, Vol. 94- No 6, May 2014.

[10] A.Praveen Prakash, N.Lakshmipathy and J.Esther Jerlin, "Problems of Housemaids in Chennai City A Study Using Combined Fuzzy Cognitive Maps" (CFCMs), International Association of Engineers, ISBN: 978-988 19252-7-5, ISSN: 2078-0958, ISSN-2078-0966, Vol.IJuly 2014. Pg.No.102-105.

[11] A.Praveen Prakash , J.Esther Jerlin and J.Bennilo Fernandes, "Dominant Problems of Rural Deprived Persons with Disability Using Fuzzy Cluster Analysis", International Association Of Engineers, ISBN: 978-98819252-7-5, ISSN: 2078-0958, ISSN-2078-0966, Vol.IJuly 2014

[12] www.thehindu.com/todays...annauniversity.../article4381 095.ece 